\title{
Correction to: The Aging Urban Brain: Analyzing Outdoor Physical Activity Using the Emotiv Affectiv Suite in Older People
}

\author{
Chris Neale $(\mathbb{D} \cdot$ Peter Aspinall $\cdot$ Jenny Roe $\cdot$ Sara Tilley $\cdot$ Panagiotis Mavros • \\ Steve Cinderby • Richard Coyne • Neil Thin • Gary Bennett • \\ Catharine Ward Thompson
}

Published online: 23 October 2017

(C) The New York Academy of Medicine 2017

\section{Correction to: J Urban Health \\ https://doi.org/10.1007/s11524-017- \\ 0191-9}

Please note that the legend to Fig. 1 has been modified since this article was originally published, and also that in Tables 2, 3 and 4, R[2] was corrected to (the now correct) R squared.

The online version of the original article can be found at https://doi.org/10.1007/s11524-017-0191-9

C. Neale $(\bowtie) \cdot$ S. Cinderby

Stockholm Environment Institute, Environment Department,

University of York, York, UK

e-mail: chris.neale@york.ac.uk

P. Aspinall

School of Built Environment, Heriot-Watt University, Edinburgh,

Scotland

J. Roe

Center for Design and Health, School of Architecture, University of Virginia, Charlottesville, VA, USA

S. Tilley $\cdot$ C. W. Thompson

OPENspace Research Centre, Edinburgh College of Art,

University of Edinburgh, Edinburgh, Scotland
P. Mavros

ETH-Centre, Singapore, Singapore

R. Coyne

Edinburgh School of Architecture and Landscape Architecture, University of Edinburgh, Edinburgh, Scotland

N. Thin

School of Social and Political Science, University of Edinburgh, Edinburgh, Scotland

G. Bennett

The Stats People, Kent, UK 